\title{
Helix-Sense Inversion in Polyaspartates
}

\author{
Shintaro Sasaki, Hiroshi Ogawa, and Shigeo Kimura \\ Department of Polymer Chemistry, Tokyo Institute of Technology, \\ Ookayama, Meguro-ku, Tokyo, 152 Japan
}

(Received April 11, 1991)

\begin{abstract}
Solid-state irreversible inversion of helix sense of poly $(\beta$ - $(p$-chlorobenzyl) Laspartate $)$ and $\operatorname{poly}(\beta$ - $(p$-methylbenzyl $)$ L-aspartate $)$ was investigated by employing circular dichroism, infrared absorption, and X-ray diffraction techniques. The molecular conformation was the right-handed $\alpha$-helix $\left(\alpha_{R}\right)$ in the as-cast film prepared from the solution in chloroform. Heat treatment caused the transition from $\alpha_{R}$ to the left-handed $\omega$-helix $\left(\omega_{L}\right)$. The crystal structure of the $\omega_{\mathrm{L}}$ forms was monoclinic (not tetragonal), i.e., the side chains do not form the fourfold helical structure. The right-to-left helix-sense inversion associated with the $\alpha$-to- $\omega$ transition was supported by the conformation energy calculation.
\end{abstract}

KEY WORDS Poly $(\beta$ - $(p$-chlorobenzyl $)$ L-aspartate $) / \operatorname{Poly}(\beta-(p$-methylbenzyl) L-aspartate) / $\alpha$-Helix / $\omega$-Helix / Helix sense /

Most of the $\mathrm{L}$ homopolypeptides form the right-handed $\alpha$-helix $\left(\alpha_{\mathrm{R}}\right){ }^{1-3}$ Its standard helix takes a unit height $p=0.150 \mathrm{~nm}$ (axial translation per residue) and a unit twist $t=100^{\circ}$ (angular separation between residues). In contrast, esters of poly(L-aspartic acid) assume the left-handed helix. Poly $(\beta$-benzyl L-aspartate) (PBLA), for instance, exists as the left-handed $\alpha$-helix $\left(\alpha_{\mathrm{L}}\right)$ in the chloroform solution. ${ }^{4-9}$ The conformation is retained in the film prepared by evaporating the solvent, but when heated above $160^{\circ} \mathrm{C}$ it is irreversibly transformed into the left-handed $\omega$-helix $\left(\omega_{\mathbf{L}}\right)$ $\left(t \equiv-90^{\circ}\right)$ with $p=0.1325 \mathrm{~nm} .{ }^{10-12}$

Poly $(\beta$ - $(p$-chlorobenzyl) L-aspartate) $\quad(\mathrm{Cl}-$ PBLA) exists as the $\alpha_{\mathrm{R}}$-helix in the chloroform solution. ${ }^{6-9}$ The film prepared from the solution exhibited an irreversible transition at about $190^{\circ} \mathrm{C}$. Takeda et al. showed by X-ray diffraction that the $\alpha_{\mathrm{R}}$-helix was transformed into the $\omega$-helix with $p=0.130 \mathrm{~nm} .{ }^{13}$ They assumed that the $\omega$-helix would be righthanded $\left(\omega_{\mathrm{R}}\right)$ because of the solid-state transition. $\mathrm{Fu}$ et al. calculated potential energies of the crystal of Cl-PBLA to support the $\omega_{\mathbf{R}}$-helix. ${ }^{14}$ Shortly afterword, however, Takeda $^{15}$ reported that the $\omega_{R}$-helix with $p=0.130 \mathrm{~nm}$ was far outside of the stable region.

Helix-sense inversion associated with the solid-state transition is possible. The $\alpha_{R}$ film of PBLA, which can be prepared by casting the solution in chloroform containing trimethyl phosphate, showed the transition into the $\omega_{\mathrm{L}}$-helix. ${ }^{16,17}$ The $\alpha_{\mathrm{R}}$ film of poly $(\beta$-phenethyl L-aspartate) (PPELA) (phenethyl $=-\mathrm{CH}_{2} \mathrm{CH}_{2}$ $\mathrm{C}_{6} \mathrm{H}_{5}$ ) exhibited the transition into the left-handed $\pi$-helix with $p=0.117 \mathrm{~nm}$ and $t=-84.7^{\circ} .{ }^{18}$ The sense inversion of PPELA was observed in the chloroform solution by adding a small amount of dichloroacetic acid (DCA) or trifluoroacetic acid (TFA) ${ }^{19}$ On the other hand, films of $\operatorname{poly}\left(N^{\varepsilon}-(p\right.$-halobenzoyl $)$ L-ornithine)s showed the transition from the $\alpha_{\mathbf{R}}$-helix into the $\omega_{\mathbf{R}}$-helix with $p=0.142 \mathrm{~nm} \cdot{ }^{20}$ These examples suggest that the unit height $p$ is a very important parameter. This will be discussed later.

The helix sense of some polyaspartates has not been clear for a long time. It is necessary 
to conclude this old issue. In this work, the structural transitions caused by heat treatment were investigated for the films of Cl-PBLA and $\operatorname{poly}(\beta$ - $(p$-methylbenzyl $) \quad$ Laspartate) (Me-PBLA).

\section{EXPERIMENTAL}

The samples of Cl-PBLA and Me-PBLA were synthesized by the $N$-carboxyanhydride method using triethylamine as the initiator in chloroform or 1,2-dichloroethane (DCE). They were recovered by precipitation with methanol, and identified by the NMR spectra of the solutions in TFA-CDCl${ }_{3}$ mixed solvent. The intrinsic viscosity measured for the solution in DCA at $25^{\circ} \mathrm{C}$ was $0.33 \mathrm{dl} \mathrm{g}^{-1}$ for Cl-PBLA and $0.42 \mathrm{dl} \mathrm{g}^{-1}$ for Me-PBLA. Density of the films was measured at $25^{\circ} \mathrm{C}$ by the flotation method using the mixed solvent of carbon tetrachloride and cyclohexane.

The circular dichroism (CD) spectra of solutions in chloroform or DCE were measured at $25^{\circ} \mathrm{C}$ with a JASCO J-20 spectropolarimeter by employing a water-jacketed quartz cell with a path length of $0.01 \mathrm{~cm}$. Very thin films for CD measurements were prepared on a quartz plate by casting the solution in chloroform at room temperature. The specimen was mounted on the sample holder equipped with a heating system, so that the incident light was normal to the plate. The effect of the birefringence due to the molecular orientation could be negligibly diminished by the treatment described below.

The differential scanning calorimetry (DSC) thermograms of films were recorded at a heating rate of $10 \mathrm{deg} \mathrm{min}^{-1}$ with a Perkin Elmer DSC Model II instrument. The infrared (IR) spectra of films prepared on a KRS plate were measured in the range 3500 to $400 \mathrm{~cm}^{-1}$ by using JASCO DS-701G grating and JEOL JIR-AQS20M FT-IR spectrophotometers.

$\mathrm{X}$-Ray diffraction patterns were taken with $\mathrm{Ni}$-filtered $\mathrm{Cu}-K_{\alpha}$ radiation. Oriented films were prepared by stroking the concentrated solution in chloroform onto a glass plate. The reflection spacings were calibrated against the 111 reflection of silicon powder sprinkled over the specimen.

\section{RESULTS}

The CD spectra of $0.3 \%$ solutions of Cl-PBLA and Me-PBLA in DCE exhibited a major negative band at $224 \mathrm{~nm}$. The magnitude of the molar ellipticity $[\theta] \sim-60000 \mathrm{deg} \mathrm{cm}^{2}$ decimol $^{-1}$ is comparable to that of PPELA. ${ }^{19}$ The molecular conformations are considered to be completely the right-handed helix.

The film of Cl-PBLA exhibited an irreversible transition by DSC at about $180^{\circ} \mathrm{C}$ with the endotherm of about $0.2 \mathrm{cal} \mathrm{g}^{-1}$ followed by the exotherm of the same magnitude. Takeda $e t$ $a l .{ }^{13}$ reported that the transition took place at $190^{\circ} \mathrm{C}$ for the sample with the degree of polymerization of 150 . Two clear transitions were observed for the Me-PBLA film; the exotherm of $2.7 \mathrm{cal} \mathrm{g}^{-1}$ at $140^{\circ} \mathrm{C}$ and the endotherm of $2.6 \mathrm{cal} \mathrm{g}^{-1}$ at $210^{\circ} \mathrm{C}$. All the transitions were not observed on the second heating process.

\section{$X$-Ray Diffraction}

The diffraction patterns were taken at room temperature for the oriented films annealed at various temperatures. The films of Cl-PBLA annealed at temperatures below $140^{\circ} \mathrm{C}$ as well as the original one showed the pattern of the $\alpha_{R}$ form, that was much improved by exposing the film to the vapor of chloroform and subsequently drying in vacuo. The unit cell was hexagonal with lateral dimension $a=1.48 \mathrm{~nm}$, and the helix pitch estimated from the layer-line spacing was $P=0.54 \mathrm{~nm}$. With a value of the unit height $p=0.15 \mathrm{~nm}$ determined from the spacing of the meridional reflection, the density was calculated to be $1.40 \mathrm{~g} \mathrm{~cm}^{-3}$, which agreed with the observed value. The film annealed at $170^{\circ} \mathrm{C}$ for $1 \mathrm{~h}$ (Figure 1a) was identified to be the $\omega$ form as mentioned below, although a few reflections of the $\alpha_{R}$ form remained. The film annealed at $190^{\circ} \mathrm{C}$ for $1 \mathrm{~h}$ exhibited two 


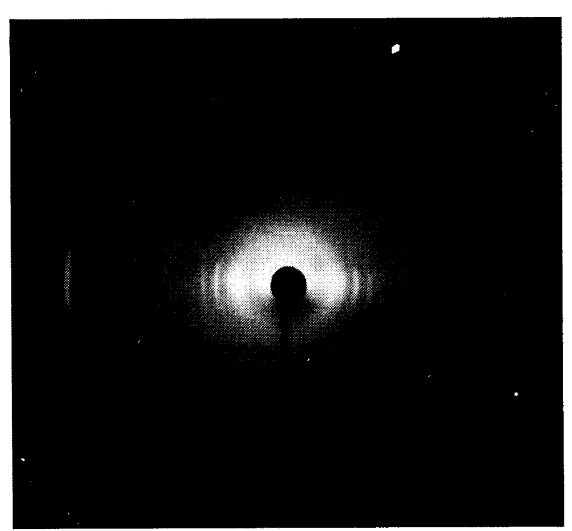

(a)

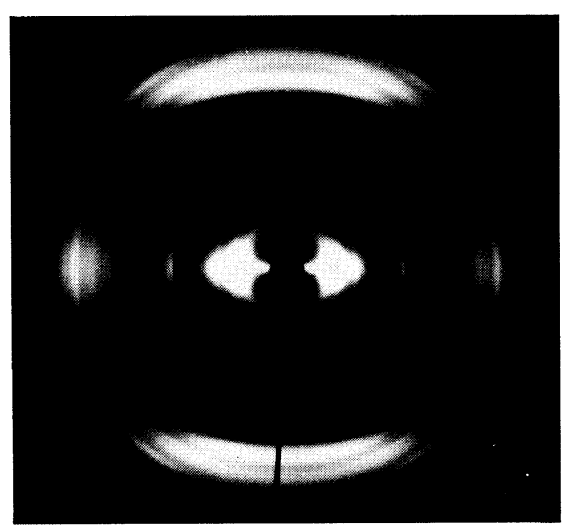

(b)

Figure 1. X-Ray diffraction patterns of the $\omega_{\mathrm{L}}$ forms of Cl-PBLA (a) and Me-PBLA (b). The orientation direction is vertical.

reflections with spacing 1.80 and $0.465 \mathrm{~nm}$ characteristics of the $\beta$ pleated-sheet structure.

Similarly, the film of Me-PBLA annealed for $15 \mathrm{~min}$ at $120^{\circ} \mathrm{C}$ was found to be the $\alpha_{\mathrm{R}}$ form (hexagonal with $a=1.49 \mathrm{~nm}, p=0.150 \mathrm{~nm}$, and $P=0.54 \mathrm{~nm}$ ). The calculated density $1.26 \mathrm{~g}$ $\mathrm{cm}^{-3}$ agreed with the observed value. The pattern of the film annealed for $15 \mathrm{~min}$ at $150^{\circ} \mathrm{C}$ (Figure $1 \mathrm{~b}$ ) was identified to be the $\omega$ form as mentioned below. The film annealed at $220^{\circ} \mathrm{C}$ indicated two reflections of the $\beta$ form at 1.83 and $0.463 \mathrm{~nm}$.

The unit height $p$ of the $\omega$ form of Cl-PBLA was determined to be $0.130 \mathrm{~nm}$ from the spacing of the meridional reflection. The fiber repeat distance $c$ was $0.52 \mathrm{~nm}$ from the layer-line spacings. These values are consistent with the fourfold $\omega$-helical structure $(c / p=4)$, as was reported by Takeda et al. ${ }^{13}$ They described the unit cell as the tetragonal with $a=2.33 \mathrm{~nm}$, but the calculated density $1.12 \mathrm{~g}$ $\mathrm{cm}^{-3}$ is not consistent with the observed value $1.45 \mathrm{~g} \mathrm{~cm}^{-3}$. From the reflection spacings observed in this work, the unit cell was determined to be monoclinic with $a=1.64 \mathrm{~nm}$, $b=1.34 \mathrm{~nm}, c=0.52 \mathrm{~nm}$, and $\gamma=99^{\circ}$. The calculated density $1.41 \mathrm{~g} \mathrm{~cm}^{-3}$ is still smaller than the observed value. In the same way, the $\omega$ form of Me-PBLA was monoclinic with $a=$
$1.66 \mathrm{~nm}, b=1.34 \mathrm{~nm}, c=0.528 \mathrm{~nm}(p=0.132$ $\mathrm{nm})$, and $\gamma=108^{\circ}$. The calculated density $1.30 \mathrm{~g} \mathrm{~cm}^{-3}$ is consistent with the observed value $1.28 \mathrm{~g} \mathrm{~cm}^{-3}$. The structures of the $\omega$ forms of Cl-PBLA and Me-PBLA are considered to be isomorphous. The side groups do not form the fourfold helix, even if the backbone assumes the fourfold symmetry.

\section{Infrared Absorption}

The spectral features were drastically changed by heat treatment at respective temperatures. The absorption wavenumbers in the frequency ranges of amide A, I, and II bands are compared in Table I with those of the poly(L-aspartate)s. ${ }^{9,11}$ It suggests that the conformations in the Cl-PBLA films annealed at 140,170 , and $190^{\circ} \mathrm{C}$ are the $\alpha_{\mathrm{R}}$-helix, the $\omega_{\mathrm{L}}$-helix, and the $\beta$ form, respectively. The Me-PBLA films annealed at 120, 150, and $220^{\circ} \mathrm{C}$ were also of $\alpha_{\mathrm{R}}, \omega_{\mathrm{L}}$, and $\beta$, respectively. These are consistent with the result of X-ray diffraction.

\section{Circular Dichroism}

The CD spectrum of the as-cast Cl-PBLA film displayed roughly a negative band of the $n-\pi^{*}$ transition at $220-230 \mathrm{~nm}$, suggesting the right-handed helical conformation. However, 
Table I. Infrared band positions for films of Cl-PBLA, Me-PBLA and poly(L-aspartate ester)s

\begin{tabular}{|c|c|c|c|c|c|}
\hline $\begin{array}{l}\text { Annealing } \\
\text { temperature }\end{array}$ & \multirow{2}{*}{ Form } & \multicolumn{4}{|c|}{ Band position $/ \mathrm{cm}^{-1}$} \\
\hline${ }^{\circ} \mathrm{C}$ & & $\begin{array}{c}\text { Amide } \\
\text { A }\end{array}$ & $\begin{array}{c}\text { Ester } \\
v(\mathrm{C}=\mathrm{O})\end{array}$ & $\underset{\text { I }}{\text { Amide }}$ & $\begin{array}{l}\text { Amide } \\
\text { II }\end{array}$ \\
\hline \multicolumn{6}{|c|}{ Cl-PBLA } \\
\hline 140 & $\alpha_{R}$ & 3280 & 1740 & 1659 & 1554 \\
\hline 170 & $\omega_{\mathrm{L}}$ & 3310 & 1736 & 1673 & 1537 \\
\hline 190 & $\beta$ & 3278 & 1727 & 1636 & 1528 \\
\hline \multicolumn{6}{|c|}{ Me-PBLA } \\
\hline 120 & $\alpha_{R}$ & 3280 & 1741 & 1659 & 1554 \\
\hline 150 & $\omega_{\mathbf{L}}$ & 3300 & 1730 & 1672 & 1535 \\
\hline 220 & $\beta$ & 3265 & 1730 & 1635 & 1525 \\
\hline \multicolumn{6}{|c|}{ Polyaspartate esters } \\
\hline & $\alpha_{R}^{a}$ & 3296 & 1741 & 1659 & 1553 \\
\hline & $\alpha_{L}^{a}$ & 3302 & 1735 & 1666 & 1557 \\
\hline & $\omega_{\mathrm{L}}^{\mathrm{a}}$ & 3296 & 1731 & 1675 & 1536 \\
\hline & $\beta^{\mathrm{b}}$ & 3275 & 1726 & 1636 & 1529 \\
\hline
\end{tabular}

a Reference 9. b Reference 11.

the features were not reproducible, and they were changed by the rotation of the sample plate in its plane. This is due to the birefringence effect of the molecular orientation. The negative peptide band seemed to be overlapped with a positive band at $\sim 230 \mathrm{~nm}$. Its intensity depended on the casting condition, and the band was most developed for the film that was exposed to the vapor of chloroform and dried in vacuo (Figure 2a). This treatment diminished greatly the birefringence effect and improved the crystallinity. From these, the 230-nm band was inferred to be contributed from the side-group chromophores. In fact, $p$-chlorobenzyl acetate, a model compound for the side group, exhibited a very strong absorption $\left(\pi-\pi^{*}\right.$ transition of $p$-chlorophenyl group) at $227 \mathrm{~nm}$. Therefore, the $230-\mathrm{nm}$ band of Cl-PBLA is the extrinsic one induced by the chiral arrangement of the side chains around the helix core.

The CD spectra of Cl-PBLA film were recorded with increasing temperature (Figure 2). The band intensity began to decrease above $120^{\circ} \mathrm{C}$, and the pattern turned upside down

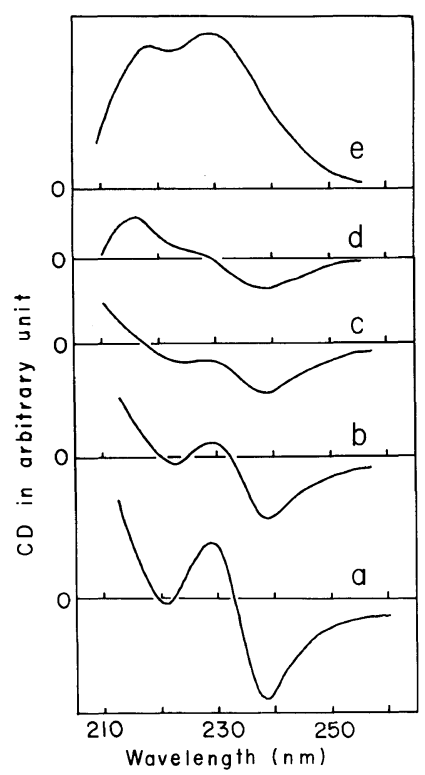

Figure 2. CD spectra of Cl-PBLA film measured on heating at 90 (a), 140 (b), 160 (c), 170 (d), and $180^{\circ} \mathrm{C}(\mathrm{e})$.

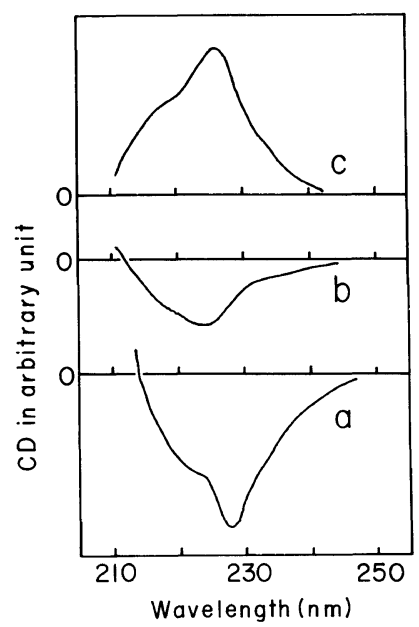

Figure 3. CD spectra of Me-PBLA film measured on heating at 25 (a), 150 (b), and $220^{\circ} \mathrm{C}$ (c).

above $180^{\circ} \mathrm{C}$. The patterns of Figures $2 \mathrm{a}-2 \mathrm{~d}$ were observed instantaneously at the respective temperatures, but the pattern of Figure 2e was observed after $10-\mathrm{min}$ annealing at $180^{\circ} \mathrm{C}$. At still higher temperature, the band was decreased in intensity, presumably owing to the $\beta$ formation. Figure 3 shows the $C D$ spectra 
of Me-PBLA films measured on heating at 25, 150 , and $220^{\circ} \mathrm{C}$. It is evident that the helix sense of these polymers was inverted into the left-handed.

\section{DISCUSSION}

\section{Transitional State}

In order to obtain the CD spectrum of Figure $2 \mathrm{e}$, it was necessary to anneal the Cl-PBLA film at least for $10 \mathrm{~min}$ at $180^{\circ} \mathrm{C}$. During a few minutes just after the temperature was raised to $180^{\circ} \mathrm{C}$, the $\mathrm{CD}$ pattern was almost flat, while the IR spectrum was characteristic of the $\alpha_{R}$-helix. The IR spectra were also recorded on heating by using a FT-IR spectrophotometer with the data acquisition time of $2 \mathrm{~min}$ for the amide I-II region. The particular spectrum that is neither of the $\alpha_{R}$-helix nor of the $\omega_{L}$-helix was not observed. The X-ray diffraction pattern of the Cl-PBLA film annealed for a short time at $180^{\circ} \mathrm{C}$ was not well-defined, but exhibited the reflections of the $\alpha_{R}$ and $\omega_{L}$ forms. The transition may proceed so that the $\alpha_{R}$-helix is sporadically broken at the initial stage, and the short $\alpha_{R}$ helices are intermingled with the disordered left-handed sequences. This state may give the flat $C D$ pattern and the IR spectrum of the $\alpha_{R}$-helix.

\section{$\omega$-Helical Conformation of Homopolypeptides}

Many calculations have been carried out for the conformation energies of polypeptides. We present here the energy map in the form dipicted against the unit height $p$ and the unit twist $t$.

Fraser et al. regarded the polypeptide chain as a ribbon of width $w$ wrapped around a cylinder of radius equal to the radial coordinate of $\mathrm{C}^{\alpha}$, and derived the correlation between $p$ and $t$ in terms of $w$ and the distance $d$ between sucessive $\mathrm{C}^{\alpha}$ atoms. ${ }^{3}$ By employing the pleated-ribbon model instead of the cylindrical one, the relationship is expressed by ${ }^{20}$

$$
p^{4}-d^{2} p^{2}+(w d t / 2 \pi)^{2}=0
$$

Most of the $\alpha$-helices $\left(|t| \sim 100^{\circ}\right)$ fall in the range admitted by the ribbon model allowing for the possible variation in the parameters (the region between two solid lines in Figure 5), but some $\omega$-helices $\left(|t| \sim 90^{\circ}\right)$ are beyond the scope. The ribbon model is evidently an oversimplification of the problem. We have attempted to describe the $p-t$ relationship by the conformation energy map.

Helix-sense inversion is characteristic of polyaspartates. We believe, however, that the energetically unfavorable conformation of the backbone will not be properly stabilized by the indefinite side-chain conformations. As was pointed out by Takeda, ${ }^{15}$ the backbone chain with $p \sim 0.130 \mathrm{~nm}$ cannot assume the $\omega_{\mathbf{R}}$-helix because of the short interatomic distance $b_{\beta}=b\left(\mathrm{O}_{1}, \mathrm{C}_{5}^{\beta}\right) \sim 0.26 \mathrm{~nm}$.

The ECEPP program ${ }^{14,21,22}$ was not employed here, since we did not intend to discuss delicate differences. By using the standard dimensions of bond lengths and bond angles given by Corey and Pauling ${ }^{23}$ and the parameters of Brant et al., ${ }^{24}$ the total potential enery was calculated for each helical conformation of a poly(L-alanine) chain as the sum of all interactions, which included torsional, nonbonded, hydrogen-bond, and electrostatic interactions between atom pairs contained in succeeding ten residues. The potential barriers for the internal rotation about the main-chain torsion angles were taken as $U_{\phi}=1.5,{ }^{24}$ $U_{\psi}=1.0,{ }^{24}$ and $U_{\omega}=20.0,{ }^{14,21,22,25}$ respectively, in unit of kcal per mol of bonds. The nonbonded interactions were taken to be of the form of the Lennard-Jones 6-12 potential, where the coefficients were computed from the Slater-Kirkwood formulation. ${ }^{24}$ The potential function of McGuire et al. ${ }^{21}$ (although it is for ECEPP) was used to treat hydrogen bonds, only when two conditions (1) the hydrogenbond length $b_{\mathrm{h}} \equiv b\left(\mathrm{O}_{1}, \mathrm{~N}_{5}\right)=0.28$ to $0.30 \mathrm{~nm}$ and (2) the angle $\tau_{\mathrm{h}}<30^{\circ}$ were satisfied. The angle $\tau_{\mathrm{h}}$ is defined as $\tau\left(\mathrm{O}_{1}, \mathrm{~N}_{5}, \mathrm{H}_{5}\right)$ for the $\alpha$ - and the $\omega$-helices. The electrostatic Coulombic interactions were calculated between 


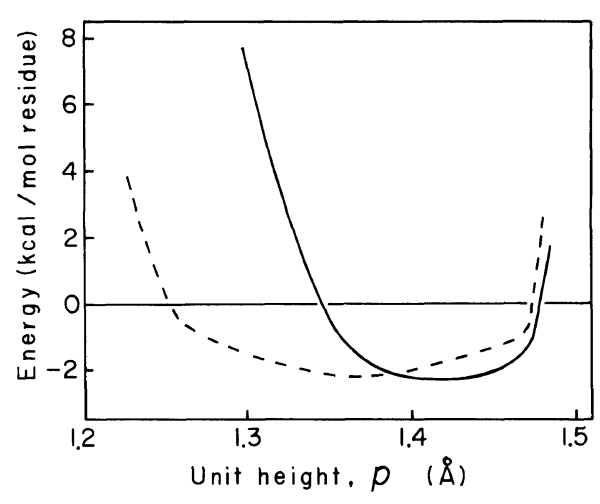

Figure 4. Conformation energies of the $\omega$-helices $(|t| \equiv$ $90^{\circ}$ ) versus unit height $p$. The energies were minimized with respect to the peptide torsion angle. Solid line, the $\omega_{\mathrm{R}}$-helics; dashed line, the $\omega_{\mathrm{L}}$-helices.

atom pairs separated by three or more bonds with the dielectric constant of $D=2$.

In advance of the energy calculation, the molecular models were geometrically examined under the criteria (1) $|\phi|$ and $|\psi|=45^{\circ}$ to $75^{\circ}$, (2) $b_{\mathrm{h}}=0.28$ to $0.30 \mathrm{~nm}$, and (3) $\tau_{\mathrm{h}}<30^{\circ}$. When the peptide torsion angle $\omega=180^{\circ}$, the $\alpha$-helices can exist with $p=0.148-0.153 \mathrm{~nm}$, while the $\omega$-helices are impossible. When we permit the nonplanar deformation of the peptide units, the $\omega$-helices become possible with $p=0.128$ $0.144 \mathrm{~nm}$. For the $\omega_{\mathrm{L}}$-helix with $p=0.130 \mathrm{~nm}$, for instance, $b_{\mathrm{h}}=0.285 \mathrm{~nm}, \tau_{\mathrm{h}}=26^{\circ}$, and $b_{\beta}=0.437 \mathrm{~nm}$ when $\phi=72.4^{\circ}, \psi=47.3^{\circ}$. and $\omega=174.8^{\circ}$.

The energy contour map was first drawn by plotting the energy values against $p$ and the torsion angle $\omega$ for each value of $t$. Then, the energies were minimized graphically with respect to $\omega$, and the minimum values were plotted against $p$. Figure 4 shows the plot for the $\omega$-helices $\left(|t| \equiv 90^{\circ}\right)$. Steep increases of energy for the helices with $p<0.126 \mathrm{~nm}$ and $p>0.146 \mathrm{~nm}$ are due to the fact that the two conditions on $b_{h}$ and $\tau_{\mathrm{h}}$ are not satisfied for these helices. The $\omega_{\mathrm{R}}$-helices with $p<0.136 \mathrm{~nm}$ are not stable in comparison with the $\omega_{\mathrm{L}}$-helices. When $p=0.130 \mathrm{~nm}$, the energy difference reaches to $9 \mathrm{kcal}$ per mol of residue.

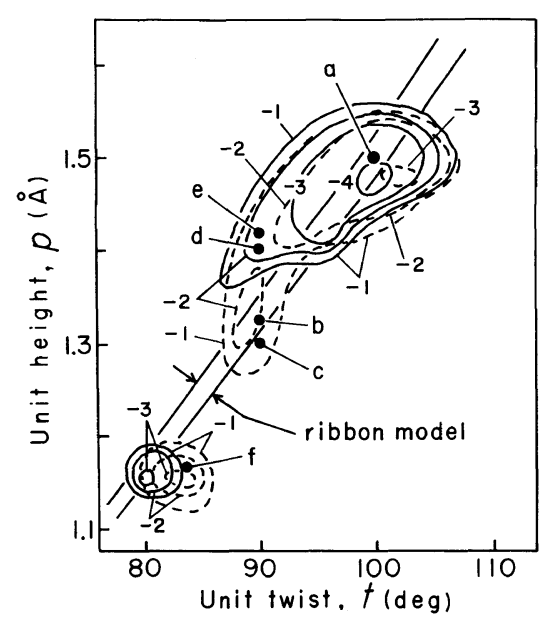

Figure 5. Energy contour map of the poly(L-alanine) helices as minimized with respect to the peptide torsion angle. The region between two solid lines is the scope admitted by the ribbon model. The figures indicate the energy values in kcal per mol of residue. Solid-line contours, right-handed helics; broken-line contours, lefthanded helics. (a) The $\alpha$-helical region ${ }^{1-3}$; (b) PBLA $\left(\omega_{\mathrm{L}}\right)^{10,12}$ and Me-PBLA $\left(\omega_{\mathrm{L}}\right)$; (c) Cl-PBLA $\left(\omega_{\mathrm{L}}\right)^{13}$; (d) poly(L-phenylalanine $)^{26}$; (e) poly $\left(N^{\varepsilon}\right.$ - $(p$-halobenzoyl $)$ Lornithine)s $\left(\omega_{\mathrm{R}}\right)^{20}$; (f) PPELA $\left(\pi_{\mathrm{L}}\right)^{18}$

The energies optimized with $\omega$ were plotted against $p$ and $|t|$ (Figure 5). The solid-line contours are for the right-handed helices, while the broken-line contours are for the left-handed helices. This map shows clearly the possible helical conformations. It elucidates why the $\omega$-helices are dispersed in the range beyond the scope of the ribbon model and why the $\omega$-helix with $p=0.142 \mathrm{~nm}$ found for poly(L-ornithine) derivatives $^{20}$ is right-handed. The $\pi_{\mathrm{L}}$-helix of PPELA is also well supported.

The monoclinic crystal structure of the $\omega_{\mathrm{L}}$ forms indicates that the side-chain interactions induced by the crystal-field effect cause deviation from the tetragonal symmetry. The analysis will be reported in the forthcoming paper.

\section{REFERENCES}

1. C. H. Bamford, A. Elliott, and W. E. Hanby, "Synthetic Polypeptides," Academic Press, New York, 1956. 
2. "Poly- $\alpha$-amino Acids," G. D. Fasman, Ed., Marcel Dekker, New York, 1967.

3. R. D. B. Fraser and T. P. MacRae, "Conformation in Fibrous Proteins," Academic Press, New York, 1973.

4. E. R. Blout and R. H. Karlson, J. Am. Chem. Soc., 80, 1259 (1958).

5. E. M. Bradbury, A. Downie, A. Elliott, and W. E. Hanby, Proc. R. Soc. London, Ser. A., 259, 110 (1960).

6. M. Hashimoto and A. Aritomi, Bull. Chem. Soc. Jpn., 39, 2707 (1966).

7. M. Hashimoto and S. Arakawa, Bull. Chem. Soc. Jpn., 40, 1698 (1967)

8. E. M. Bradbury, B. G. Carpenter, and H. Goldman, Biopolymers, 6, 837 (1968).

9. E. M. Bradbury, B. G. Carpenter, and R. M. Stephens, Biopolymers, 6, 905 (1968).

10. E. M. Bradbury, L. Brown, A. R. Downie, A. Elliott, and R. D. B. Fraser, and W. E. Hanby, J. Mol. Biol., 5, 230 (1962).

11. D. B. Green, F. Happey, and B. M. Watson, Eur. Polym. J., 6, 7 (1970).

12. J. P. Baldwin, E. M. Bradbury, I. F. McLuckie, and R. M. Stephens, Macromolecules, 6, 83 (1973).

13. Y. Takeda, Y. Iitaka, and M. Tsuboi, J. Mol. Biol., 51, 101 (1970).
14. Y.-C. Fu, R. F. McGuire, and H. A. Scheraga, Macromolecules, 7, 468 (1974).

15. Y. Takeda, Biopolymers, 14, 891 (1975).

16. V. Giancotti, F. Quadrifoglio, and V. Crescenzi, $J$. Am. Chem. Soc., 94, 297 (1972).

17. H. Kyotani, H. Kanetsuna, M. Ōya, J. Polym. Sci. Polym. Phys. Ed., 15, 1029 (1977).

18. S. Sasaki, Y. Yasumoto, and I. Uematsu, Macromolecules, 14, 1797 (1981).

19. H. Toriumi, N. Saso, Y. Yasumoto, S. Sasaki, and I. Uematsu, Polym. J., 11, 977 (1979).

20. S. Sasaki and Y. Iwanami, Macromolecules, 21, 3389 (1988).

21. R. F. McGuire, F. A. Momany, and H. A. Scheraga, J. Phys. Chem., 76, 375 (1972).

22. F. A. Momany, R. F. McGuire, A. W. Burgess, and H. A. Scheraga, J. Phys. Chem., 79, 2361 (1975).

23. R. B. Corey and L. Pauling, Proc. R. Soc. London, Ser. B, 141, 10 (1953)

24. D. A. Brant, W. G. Miller, and P. J. Flory, J. Mol. Biol., 23, 47 (1967).

25. G. N. Ramachandran, A. V. Lakshminarayanan, and A. S. Kolaskar, Biochimi Biophys. Acta, 303, 8 (1973).

26. O. Yamashita, T. Yamane, T. Asada, S. Yamashita, and T. Yamashita, Polym. J., 11, 763 (1979). 